\title{
How does Modern Process Automation understand the Principles of Microbiology and Nature
}

\author{
Ari Jääskeläinen ${ }^{1}$ Risto Rissanen ${ }^{1}$ Asmo Jakorinne ${ }^{1}$ Anssi Suhonen ${ }^{1}$ Tero Kuhmonen ${ }^{1}$ \\ Tero Reijonen ${ }^{1}$ Eero Antikainen ${ }^{1}$ Anneli Heitto ${ }^{2}$ Elias Hakalehto ${ }^{2}$ \\ ${ }^{1}$ School of Technology, Savonia University of Applied Sciences, Finland, ari.jaaskelainen@ savonia.fi \\ ${ }^{2}$ Finnoflag Oy, Finland, elias.hakalehto@gmail.com
}

\begin{abstract}
Future biorefineries will work according to the principles of Nature, using microbes and enzymes for valorizing wastes and other biomass into biofuels, other bioenergy substances, organic platform chemicals, and organic fertilizers. A mobile biorefinery pilot plant was engineered and manufactured in Finland and tested in Finland, Poland and Sweden with various biowastes within ABOWE project. The main purpose of the ABOWE Biorefinery pilot plant tests was to give a reliable "proof of concept" on the industrially important substances producible in a sustainable way. This goal was achieved successfully, and several overall difficulties were overcome during the testing in three countries.
\end{abstract}

Keywords: bioprocess, biorefinery, biowaste, consolidated bioprocessing, undefined mixed cultures, anaerobiosis

\section{Introduction}

Biotechnology deals with processes that are based on naturally occurring phenomena. Bastin and Dochain (1990) define bioreactor as a tank in which several biological reactions occur simultaneously in a liquid medium. The biological reactions which are involved in the process can be classified as microbial growth reactions/microbiological reactions and enzyme catalyzed reactions/biochemical reactions. The growth of the microorganisms (bacteria, yeasts, etc.) proceeds by consumption of appropriate nutrients or substrates such as carbon, nitrogen and oxygen. Preferably environmental conditions (temperature, $\mathrm{pH}$, etc.) are optimized. The cell growth is associated with the enzymatic reactions in which some reactants are transformed into products through the catalytic action of enzymes. (Bastin and Dochain, 1990)

Favorable environmental conditions for microorganisms should be maintained all the time. Exceeding boundary values regarding conditions leads to slowing of the production rate, and there is often no other way than to readjust or restart. The failure of the process does not always require even crossing the threshold, but this may also happen due to circumstances in which some of the harmful microbes take over.

To process control and automation the multiple variables in a mixed microbial culture set high demands. Parameters in terms of automation are, e.g., $\mathrm{pH}$, temperature, sugar balance, dissolved oxygen and gas mixtures. Each of the above-mentioned variables has its own control and adjustment aspects. This is the socalled multivariable system, in which there are dependencies between parameters. Each parameter's effects on microbial activity should be understood in order to get the optimal outcome from the automation and process design. The principles of fuzzy logic might be needed. Temperature control alone is already a challenging thing, because the process itself generates heat, which should be predicted. Not to mention the other variables. The phenomena are very unstable and cross-effects are common. For control engineering and process control these are demanding cases to adjust and measure the variables in order to reach the desired outcomes.

Processes cannot be adjusted only with traditional methods used in heavy industry but events have to be controlled with a technique called bioautomation. In addition to the physical sensors there is information required that might not even be possible to get with concentration analysis measurements. There is a need to go deeper into the events even at the cellular level for which micro- and nanotechnology bring along new opportunities.

Knowledge of processes is very important in automation engineering. Microbiology often deals with more difficult phenomena than regular process chemistry does. The problems are almost impossible to be solved otherwise than through close cooperation between experts from various fields.

Future biorefineries will work according to the principles of Nature, using microbes and enzymes for valorizing wastes and other biomass into biofuels, other bioenergy substances, organic platform chemicals, and organic fertilizers. The concept of 'waste' will become unnecessary in industries, communities, agriculture and forestry as all materials are being refined and recycled. The ABOWE (Implementing Advanced Concepts for 
Biological Utilization of Waste, 12/2012-12/2014) project, led by Savonia University of Applied Sciences, and its two pilot plants, have paved the way for this industrial revolution. ABOWE project belonged to the EU Baltic Sea Region Programme 2007-2013. (Jääskeläinen and Hakalehto, 2015)

The novel biorefinery concept, innovated and developed by Adjunct Professor Elias Hakalehto, (Finnoflag Oy and University of Eastern Finland), was one of the two platforms of the ABOWE project. The second platform was biogas production with the dry digestion technology piloted under the supervision of Ostfalia University of Applied Sciences, Germany. ABOWE was an extension project for REMOWE project (Regional Mobilization of Sustainable Waste to Energy Production 9/2009-12/2012) to continue with these two promising technologies to piloting phase. (Hakalehto et al, 2016a)

Savonia University of Applied Sciences invested in the ABOWE project in a mobile biorefinery pilot plant. In this biorefinery plant biodegradable wastes are valorized to valuable chemical and energy products with the aid of microbes and their enzymes, in the same way as in the natural environments.

The pilot plant engineering team consisted of Finnoflag Oy experts and Savonia's engineering teachers, project engineers and engineering students. The project team was built so that teaching was integrated as widely as possible already at the planning stage of the process. Versatile knowledge of process and instrumentation, layout, mechanical, electrical, automation, IT, environmental and manufacturing was combined for the pilot plant engineering and manufacturing during 2013.

Savonia manufactured the pilot plant in front of its educational workshop. In the pilot plant manufacturing, several locally operating industrial enterprises were participating as component suppliers. Also many trainees from Savo Vocational College, Finland, participated in the manufacturing of the pilot plant. Altogether over 50 persons were involved in the pilot plant engineering and manufacturing in Finland. There was not much available model, and practical experience about effects of various functions was mostly lacking. Savonia's personnel instructed the project, brought engineering know how to the project and performed equipment purchases. (Jääskeläinen and Hakalehto, 2018)

The biorefinery pilot plant was completed in January 2014 and was tested in Finland with waste water treatment sludge at a fluting factory, in Poland with potato waste from chips factory and in Sweden with chicken manure and slaughterhouse waste during 2014.

\section{Materials and Methods}

Objectives of the ABOWE project regarding the mobile biorefinery pilot plant were to test

- Effective pretreatments and hydrolysis of various biodegradable wastes.

- Enhanced natural microbial bioprocess for the upstream production of fuels and chemicals.

- Preliminary planning of the simultaneous product collection.

The goal of the ABOWE project and the mobile pilot plant was to provide "proof of concept" on the ways, how biomass waste materials could be used as raw materials. The products were biofuels, bioenergy, organic platform chemicals and organic fertilizers. These should be produced in an economically feasible way, with the help of micro-organisms. (Hakalehto et al, 2016b)

The biorefinery process is novel in terms of improved productivity, low initial investment costs and versatile product opportunities. The production exploits results from the research conducted in the Finnoflag laboratory since 1997 with the PMEU enhanced cultivation unit (Portable Microbe Enrichment Unit), and in larger vessels. As various products are produced faster, the production plant size reduces enabling lower investment. Moreover, the total duration of the process can be shortened and end product concentrations increased. (Hakalehto et al, 2016b)

There are four main tanks in the mobile biorefinery pilot plant's process (Hakalehto et al, 2016b):

1. HOMOGENIZER is the first main tank. Attached to it is a biomass crusher and the tank has an effective mixer. Water content can be adjusted partially in Homogenizer from a water tap. Homogenizer is also one of the three recycled and modified tanks in the pilot plant used for the upstream bioprocess. In Homogenizer various biomasses are mechanically broken in microand macroscale. Their dry weight is measured in the onsite lab room and the total masses of solid and liquid substrates are measured with a weighing sensor installed in the leg of the tank.

2. HYDROLYZER is a reactor with thermostat and $\mathrm{pH}$ control for producing, maintaining and adjusting the optimal conditions for chemical and/or enzymatic hydrolysis of the macromolecules in the substrate biomasses. Main operating parameters are the water content, fill in level, temperature (can be lifted up to 80 degrees Celsius), $\mathrm{pH}$ of the biomass, viscosity and the hydrolysis time. Hydrolyzer temperature is controlled with a control sequence whose parameters can be set from the control room. The purpose of the sequence is to perform the hydrolysis of the raw material and to kill harmful microbes so that the batch would be ready to be fed in the Bioreactor. Also $\mathrm{pH}$ is started to be adjusted for the coming process phases. 
3. BIOREACTOR is the sole entirely novel big tank in the pilot plant. It has been manufactured by (Brandente Oy, Kuopio, Finland) according to the instructions of the innovator (Finnoflag Oy, Siilinjärvi, Finland) and Savonia. The patented design is based on numerous bioprocess runs in Finnoflag Oy's laboratory projects preceding the ABOWE project. Different homogenized and hydrolyzed biomasses are processed in adjustable gas conditions in the Bioreactor in order to produce biofuels, biogases and biochemicals by the metabolic activities of bacteria and other microorganisms. The volume of the tank is around 300 liters of which effective volume is around 200 liters.

An optimal gas mixture is introduced to the Bioreactor from gas bottles and air compressor via a gas mixer. Typical gases besides the air are carbon dioxide and nitrogen depending on the specific requirements of the microbial culture. An optimal mixture is introduced via aeration discs and rings from two layers in the Bioreactor. The gas flow is at the same time performing the airlift principle in the Bioreactor mixing. There is not any mechanical stirring system, e.g., to avoid shear forces in the process broth.

There is a two-step process for producing the microbiological inocula: first in the PMEU equipment (Portable Microbe Enrichment Unit) (Samplion Oy, Siilinjärvi, Finland), and then in the seed fermenters connected to the Bioreactor. In PMEU it is possible to get homogenous cultures into same active growth phase in a few hours of cultivation (Hakalehto and Heitto, 2012). Besides ABOWE version, the PMEU has been productized earlier for environmental, clinical, food, and other hygienic control purposes (Hakalehto, 2012).

Additional substances and $\mathrm{pH}$ adjustment chemicals are fed to a circulation from the Bioreactor back to the Bioreactor, run by a circulation pump. Thus substances can easier be mixed with the mass and local higher concentrations are not occurring in the Bioreactor. At the same time it is possible to take necessary samples from this circulation. Circulation velocity or the reference value for flow speed $(1 / \mathrm{min})$ can be set from the control room.

During the process runs $\mathrm{pH}$, dissolved oxygen, temperature, total volume (biomass input and process fluid outflow), as well as the gas mixing and measurement are adjusted by the process control system together with real time operating activity by the personnel on site and via $3 \mathrm{G}$ connection to the pilot plant. The gaseous products are recorded from the volatile outflow of the Bioreactor prior to the stabilization.

A schematic drawing of the Bioreactor is presented in Figure 1.

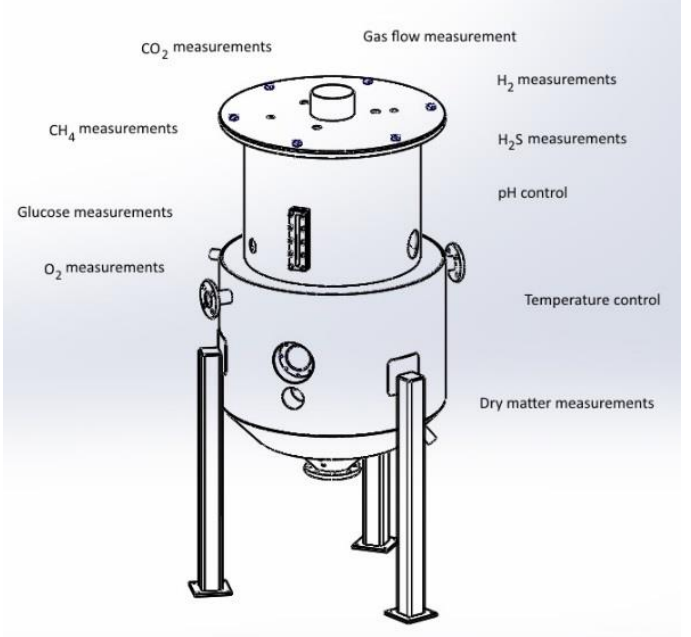

Figure 1. Schematic drawing of ABOWE Bioreactor with indication of various measurement parameters. Lecturer Anssi Suhonen, Savonia based on instructions from Adj. Prof. Elias Hakalehto, Finnoflag Oy.

4. STABILIZER was modified from a food industry boiling tank into a cooled collection unit of the bioprocess fluid containing liquid and possibly solid products of the pilot plant. In Stabilizer the temperature is decreased to 15-18 degrees Celsius from the usually much higher production temperatures in order to avoid losses in the product concentrations after the process.

The process fluid was further analyzed with Nuclear Magnetic Resonance (NMR) by Professor Reino Laatikainen at the University of Eastern Finland in Kuopio (Laatikainen et al, 2016). Ostfalia University of Applied Sciences in Germany provisionally experimented the downstream processing of some of the bioprocess products, under the supervision of Professor Thorsten Ahrens.

The original idea of the piloting experiments was to study the combination of gaseous, liquid and solid phases in the Bioreactor in order to produce biofuels and bioenergy, organic platform chemicals and organic fertilizers, or their raw materials. Breaking the biochemical process into bits and pieces could form this basis for any experimentation in the future. (Hakalehto et al, 2016b)

\section{Results and Discussion}

\subsection{Tests in Finland}

The first ABOWE testing site was Powerflute Oyj Savon Sellu fluting factory's waste water treatment plant in Kuopio, in Eastern Finland during FebruaryMarch 2014. The climate conditions with temperatures between $-25^{\circ} \mathrm{C}$ and $-30^{\circ} \mathrm{C}$ were harsh so the functions of the pilot plant were put straight into a real "climate test". Liquids tend to get frozen in the pipes during their pumping into the pilot plant. Also the substrate for the tests, the dried sludge from the waste treatment plant 
was rapidly cooling down in the piles where it was collected from the activated sludge pools. Another raw material for the experiments was the incoming waste water. In the factory there are actually two separate systems, namely the pulp factory and the corrugated carton board (fluting) machine. Waste waters from both machines arrive to the waste water treatment plant. The original raw material wood chips are treated with many chemicals during the production process. (Hakalehto et al, 2016b; Hakalehto et al, 2016c)

Products and services from the test runs at Savon Sellu were:

- Ethanol, Butanol

- 2,3-butanediol

- Organic acids

- Hydrogen

- Fertilizer biomass

- Biogas

- Purified waste water

- Decreased waste treatment expenses

- Lesser environmental and climatic load

The initial break-in test runs and international training period were carried out during the testing at Savon Sellu waste water treatment plant in January and February 2014. The first 3-4 runs were targeted for pretreating the available substrate in the pilot plant process. Both anaerobic and aerobic test runs were accomplished. In all cases, regardless of the hygienization during the hydrolysis step, the natural microflora from the activated sludge treatment process pools, especially the sulfur bacteria, contaminated the Bioreactor process broth. They were then restricted by the inoculated Klebsiella/E.coli strains which were preincubated in the Bioreactor as a nutrient bed type of inoculum. This same strategy was later used in the two anaerobic cultivations with Clostridium sp. (Hakalehto et al, 2016b) An example of the process development at the Finnish testing site is presented in Table 1.

Table 1. Description of process development outlines in the Finnish runs at the Savon Sellu fluting factory site (Hakalehto et al, 2016b)

\begin{tabular}{|c|c|c|c|}
\hline & $\begin{array}{l}\text { General } \\
\text { problem }\end{array}$ & Practical solution & Potential solution \\
\hline 1. & $\begin{array}{l}\text { Diffusion } \\
\text { limitation }\end{array}$ & $\begin{array}{l}\text { Gas flow adjustment } \\
\text { Homogenisation with } \\
\text { effective hydrolysis }\end{array}$ & $\begin{array}{l}\text { Improved } \\
\text { Bioreactor design } \\
\text { for full scale plants }\end{array}$ \\
\hline 2. & $\begin{array}{l}\text { Disturbing } \\
\text { organisms }\end{array}$ & $\begin{array}{l}\text { Speeded up } \\
\text { inoculations } \\
\text { Nutrient beds } \\
\text { Hygienization of } \\
\text { waste }\end{array}$ & $\begin{array}{l}\text { Consolidated } \\
\text { Bioprocessing }\end{array}$ \\
\hline 3. & $\begin{array}{l}\text { Productivity } \\
\text { problems }\end{array}$ & Mixed wastes & $\begin{array}{l}\text { Simultaneous } \\
\text { downstreaming for } \\
\text { blocking biological } \\
\text { down regulation }\end{array}$ \\
\hline 4. & $\begin{array}{l}\text { Too low raw } \\
\text { material } \\
\text { concentration }\end{array}$ & $\begin{array}{l}\text { Process fluid } \\
\text { circulation } \\
\text { Nutrient beds }\end{array}$ & $\begin{array}{l}\text { Better pumps and } \\
\text { valves }\end{array}$ \\
\hline
\end{tabular}

Microbiologically one of the most influential process chemical addition is the use of sulfuric compounds in the Savon Sellu factory process, which eventually led to the enrichment of $\mathrm{H}_{2} \mathrm{~S}$ liberating bacteria into the gas emission flow from the Bioreactor when the sludge was used as substrate. As one of the precautions for this liberation of the toxic gas flow, a specific alarm system was installed. All gases, however, were directed out of the pilot plant which completely prevented their accumulation inside, and thus the formation of occupational hazards. The general safety of the unit had been discussed beforehand with North Savo Regional Rescue Services and the authorities were satisfied with the pilot plant and the plans for its short testing period. (Hakalehto et al, 2016c)

The $\mathrm{H}_{2} \mathrm{~S}$ formation was on a very high level in most of the test runs. Consequently, the fed-batch function of the pilot plant was not possible to get tested during the short time-window at the Savon Sellu testing site. Furthermore, a major part of the planned time was needed for adjustments of the heating and cooling system as three of the four main process tanks were purchased as recycled industrial equipment and modified for the bioprocess use with the principle of sustainability. (Hakalehto et al, 2016c)

Despite the very short time schedule for the start-up phase, promising results were obtained. The primary purpose of the first tests in Finland was mainly to get familiar with the relatively complicated system of the equipment with computer control, numerous measurements, as well as temperature, $\mathrm{pH}$ and gas adjustments. Several sensors proved to be useful with secondary screens in the process room, besides the process control system in the control / laboratory room. (Hakalehto et al, 2016c)

The basic principles for steering the pilot plant were learnt, and their implementation gave promises for the potential of future bioprocess development. In the startup phase any result from the biological multi-variable process is giving valuable information for future experiments. Improvement of the pilot plant equipment is still needed, one target being such pumps that are capable to move raw material with dry weight higher than $10-15 \%$. Increasing this value would uplift also the yield and productivity of various biochemicals. (Hakalehto et al, 2016c)

On the bioprocess side, the non-aseptic principle was tested, because it could at best lower the investment costs of the process equipment to one tenth in the large production units. Therefore, the natural microflora from the waste water pools and the activated sludge caused many problems and produced overgrowth which almost took over the Bioreactor in the beginning of the experimentation. Measures for abating the background flora were attempted, but these trials were not completed during the short experimentation period. However, the nutrient bed approach with inoculation of the production 
organisms prior to the major substrate addition seemed to be the correct way to tackle most of the problems caused by the background flora. (Hakalehto et al, 2016c)

One significant result was the production of the hydrogen gas from the waste sludge, observed earlier in the Finnoflag Oy's laboratory, which could provide 150-300 kWh of electricity daily from the Savon Sellu fluting factory's waste waters. This value was estimated from the preliminary results without any continued optimization or process development. The generation of molecular hydrogen was taking place parallel to the production of liquid chemicals, whose production levels were subjected to improvement due to the preliminary nature of the testing. The diminishment in the environmental load of Savon Sellu waste water was already comparable to the biogas process, and actually the biorefining for chemical products could be combined with cascading biogas production for the highest decrease in the climatic effects of the waste water treatment. This gas emission could be combined with methane from another reactor system in order to obtain hytane (hydrogen plus methane) gas mixture for energy production. (Hakalehto et al, 2016c)

\subsection{Tests in Poland}

The testing site in Poland was the waste management center of ZGO Gać Ltd near Wrocław, in Lower Silesia during May-early July 2014. The main substrates were potato peels from a chips factory and separately collected biowaste from households and restaurants. These substances were rather easily degradable. The potato starch had been readily degradable source of hydrolysable biomass in the experiments preceding ABOWE, carried out by Finnoflag Oy in Finland (Hakalehto et al, 2013). Then record levels of 2,3butanediol productivities had been achieved $(8 \mathrm{~g} / \mathrm{l} / \mathrm{h})$. This degradative process was based on the studies with the members of Enterobacteriaceae family of facultatively anaerobic bacteria, particularly of the genus Klebsiella (Hakalehto, 2013; Hakalehto et al, 2008).

In the tests participated 24 students and six experts from Wrocław University of Technology together with Finnoflag $\mathrm{Oy}$. The substrate was of a "carboxylic platform" type (den Boer et al, 2016a). In the experiments with sole Polish potato waste (consisting mainly of potato peels), ethanol was the principal product, besides the high amounts of hydrogen produced from the waste. Hydrogen measurement was limited to $10000 \mathrm{pm}$ due to calibration of the gas measurement unit. The hydrogen production exceeded $10000 \mathrm{ppm}$ for long periods during each run. It should be taken into account that this flow of volatiles was produced into a carrier gas flow which was not diminished in the calculations. Consequently, the levels of biohydrogen production could be considered as promising ones. (Hakalehto et al, 2016b)

In the beginning of the Polish testing period, heterogeneous composition of sorted biowaste was believed to disturb the process set up and control. However, this did not turn out to be a considerable problem. Instead, adding miscellaneous food waste to the process clearly boosted the production of various organic chemicals which reached a few percent of the total volume, and $15-20 \%$ of the dry weight. During these experiments the highest yields were not achieved or even tried to get achieved due to time limitations. In the future, efforts should be made to concentrating the feedstock into adequately high substrate concentrations. However, with more time and some technical upgrading of the pilot plant equipment, still much higher levels and productivities could be achieved with optimized processes. This is deducible also from the amount of unused substrate in the process residues. However, even by the current experimentation several industrial levels of biochemical productions were obtained. (Hakalehto et al, 2016b)

The analysis results from on-site Gas Chromatography (GC) and the Nuclear Magnetic Resonance (NMR) studies, the latter conducted by Prof. Reino Laatikainen, School of Pharmacy, University of Eastern Finland, produced somewhat different results. In some runs the levels were about 2-3 times higher in the former than the latter. This could be due to the storing of samples for the NMR in cold and transportation them to Finland, where they were analyzed much later on. It is then quite obvious that some changes could occur. Otherwise the NMR gave clear identification of the substances whereas the GC seemed to give some peaks close to each other which caused difficulties in the identification of the compounds. This was the case especially with 2,3butanediol and valeric (pentanoic) acid. The latter was not expected to come out in the fermentation in large quantities but it was produced in high amounts. This organic acid was probably resulting from the condensation of acetic acid (two carbon molecule) and propionic acid (three carbon molecule). Both 2,3butanediol and valeric acid could be valuable chemicals for producing butadiene (a raw material for plastics, synthetic rubber) and in cosmetic products (called also "2,3-butylene glycol"). (Hakalehto et al, 2016b)

Otherwise GC turned out to be a rather reliable method and it was successfully used in the pilot plant tests in Finland, Poland and Sweden. In all sampling and sample treatments it was important to separate the solids quickly enough for preventing any bacteriological activity caused degradation. The amount of products bound to the precipitating solid fraction could not be analyzed, so in future applications separation of the products in the liquid forms needs to be taken into consideration. In any case, the Polish testing period 
indicated clearly the biorefinery concept's potential for producing soluble chemicals for industrial raw materials. Likewise it indicated the potential to produce hydrogen in these processes. In fact, the hydrogen production started quickly, and it was produced on remarkable levels even though this flow was integrated into the carrier gas. (Hakalehto et al, 2016b)

Two microbe species were applied in the Polish biorefinery process runs as additional inocula to the process broth, namely Klebsiella mobilis and Escherichia coli. These strains had been reported to metabolize glucose into organic acids, ethanol and 2,3butanediol as a result of joint activities of their mixed cultures where a symbiotic relation between the strains developed (Hakalehto et al, 2008). The initial five runs were performed using potato waste as the single substrate. In these tests ethanol and acetic acids were main products. Among the gaseous products, hydrogen formation took place at elevated levels. Potato waste, however, seemed not to contain sufficient microelements to maintain generation of high level, longer chain products. It seems probable that the nitrogen and calcium levels could be limiting factors for the microbes. A significant improvement could be obtained when the kitchen biowaste were used as the initial raw material. With NMR analyses the presence of such substances as butyric acid, propionic and valeric acid at elevated levels were confirmed. Especially in the Polish Runs 7 and 8 high conversion rates to carboxylates, 0,75 and $0,81 \mathrm{~mol} / \mathrm{mol}$ glucose respectively, to longer chain carboxylic acids were measured. Compared to $\mathrm{C} 2-\mathrm{C} 4$ carboxylic acids, longer chain carboxylic acids are superior in terms of energy content and hydrophobic nature, facilitating the downstream processing (Spirito et al, 2014). The results confirmed, that the biorefinery processes offer a clear advantage over conventional biowaste treatment technologies in terms of useful products which can be generated. (den Boer et al, 2016a)

\subsection{Tests in Sweden}

During the Swedish tests the pilot plant was located at a chicken farm Hagby Gård in Enköping. The farm produces roughly 800 chickens a week for slaughter (2014). The slaughterhouse, as well as their own store, is located in Västerås. (Hakalehto et al, 2016a; Schwede et al, 2017)

Finnoflag Oy led the Swedish tests which were organized by experts from Mälardalen University together with the Hagby Gård and also Savonia University of Applied Sciences. During the tests at Hagby farm, some $30 \%$ of chicken slaughterhouse waste was mixed with other biomass. The latter were chicken manure from the farm, some saw dust used as litter in the bird shelters, and occasionally some waste apples available at the farm. As additives were occasionally also used some potato flour, sugar or blueberry soup. Considerable problems emerged during the testing due to the pumps' inability to operate with the sticking feathers and the small stones originating from the bird digestion. The pumps got easily stuck with these miscellaneous particles or substances even though they had enough capacity for forwarding the biomass. Therefore, the final density and dry mass content was too low for higher product yields. However, the proof of concept was clearly demonstrated, and valuable products formed within the limits of the raw material offered. A tedious mixture of protein and lipid wastes was possible to convert first into yellowish milky broth were no particles were detected practically in overnight, and further to a solution of organic acids and alcohols. This could happen without significant loss in the dry weight of the soluble substances. (Hakalehto et al, 2016b)

The slaughterhouse located some $40 \mathrm{~km}$ from the testing site so the chicken inner organs and other remaining parts were cooled for transportation. This cooling was probably not effective enough, which provided time for the mixed flora in the wastes to develop too far for the optimal substrate use in the biorefinery. In order to boost the biochemical production after the hygienization (in Hydrolyzer), strains of Clostridium acetobutylicum and Clostridium butyricum were inoculated. It is noteworthy that, even though they are generally considered as obligate anaerobes, these bacteria have been reported to withstand some oxygen occasionally. They also could stay active under 100\% oxygen flow (Hell et al, 2010). This was used as a selective factor during the experimentation. Earlier it had been reported that the clostridial growth was boosted also by $\mathrm{CO}_{2}$, which has been exploited for the rapid start of growth (Hakalehto, 2015; Hakalehto and Hänninen, 2012). In some runs, subsequent inoculations seemed to initiate the production of some chemicals which is implying to some quarum sensing type of signaling in the bacterial cultures. Also, addition of blueberry soup into some test runs clearly had a positive boosting effect which indicates the need for some trace elements and minerals for the best production levels. (Hakalehto et al, 2016b)

The expected products were short-chained organic acids, like acetate, propionate and butyrate that, if there had been more time for the test runs, could have been reduced to alcoholic and aliphatic substances. Other expected products were hydrogen and some 2,3butanediol. Further, analysis by the NMR in Finland revealed some additional products such as valeric (pentanoic) acid and amyl alcohol. The latter was probably produced partially from the apple waste, but could get obtained also without the apples. Acetate and propionate derived from the bacteriological activity, can react with each other to form valeric acid, which also is a valuable product with a price 2-3 times of 2,3- 
butanediol. (Hakalehto et al, 2016a; Hakalehto et al, 2016b)

The results show that products have been obtained both in the aerobic and anaerobic experiments. Production rates are higher when easily accessible carbohydrates and sugars are available. The highest levels of ethanol, acetic acid, propionic acid and 2,3butanediol were obtained in the second test. Easy accessed carbohydrates in the added sugars and potato flour might explain this. Also the first run where sugar was also added showed somewhat higher product levels than later runs. (Hakalehto et al, 2016a)

Due to the glucose limitation of the raw material, Klebsiella was not effective for 2,3-butanediol production in this setting. Higher glucose levels could be facilitated by pump and mass transfer improvements, which could make it possible to gain industrial levels. Several organic acids were produced in high quantities. Improved pretreatments and elevated small carbon molecules would increase the yield also in their production.

During intensive bacteriological activity periods hydrogen production was rather high, which could give leads to development of biohydrogen production from the organic wastes, such as the animal or plant residues from the agriculture. (Hakalehto et al, 2016a)

Surprisingly, ABOWE tests in Sweden produced significant amounts of organic chemicals regardless of the low carbohydrate concentrations in the beginning of the experiments. This indicated the use of proteins and fats as substrates by the microbes. The microflora consisted of the natural microbiota and the added industrial strains which were managed to get function relatively well together. The yields and productivities could be increased by improvements to the process and to the equipment. (Hakalehto et al, 2016a; Schwede et al, 2017)

In an overall consideration, the Swedish testing period gave a proof of concept on a reasonable method to deal with tedious wastes from slaughterhouse and bird farm within a short time-window. This approach could serve as a significant model for the activities in many countries, where the chicken litter forms a considerable environmental problem. (Hakalehto et al, 2016b)

\subsection{Technical Functioning of the Mobile Biorefinery Pilot Plant}

During the project many challenges were faced in the designing and construction of the mobile pilot plant which would be both a real production process as well as a research laboratory. For instance, temperature and $\mathrm{pH}$ control for a process that is run by living organisms, brought along many questions to be solved.

The weighing of Homogenizer did not function well enough so the amount of solid matter could not be properly measured. Moreover water and other substances were added to the process from other ways than through measurements. This complicated the testing operations and the analysis thereof, as the amounts of raw materials were not always reliably known.

A lot of heat energy was needed for the hydrolysis and in the pilot plant the heating of hydrolysis functioned well. Using warm water, from a hot-water tank, as an energy source was a good solution. In an industrial scale production plant this should be recovered in cooling and used for treatment of new raw material. This means that for a viable treatment the process needs to be a continuous one and energy has to be transmitted with a heat exchanger always to new raw material. In this pilot plant this efficient energy consumption could not be implemented.

In the following figures, there are presented the measured temperature and $\mathrm{pH}$ values from Hydrolyzer and Bioreactor during a selected test run from all three countries. The time axis is the same in the figures of Hydrolyzer and Bioreactor.

In Figures 2 and 3 the temperature and $\mathrm{pH}$ measurement data from Hydrolyzer and Bioreactor during the final test run in Finland are presented.

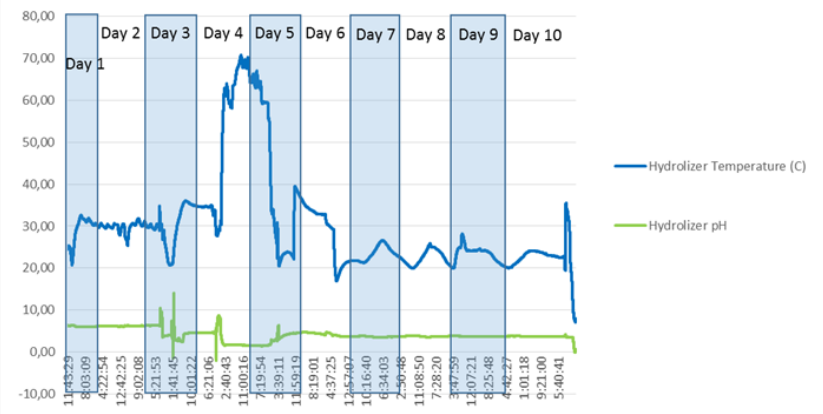

Figure 2. Hydrolyzer Temperature and $\mathrm{pH}$ during the Finnish Run 6 (24.3.2014 - 3.4.2014).

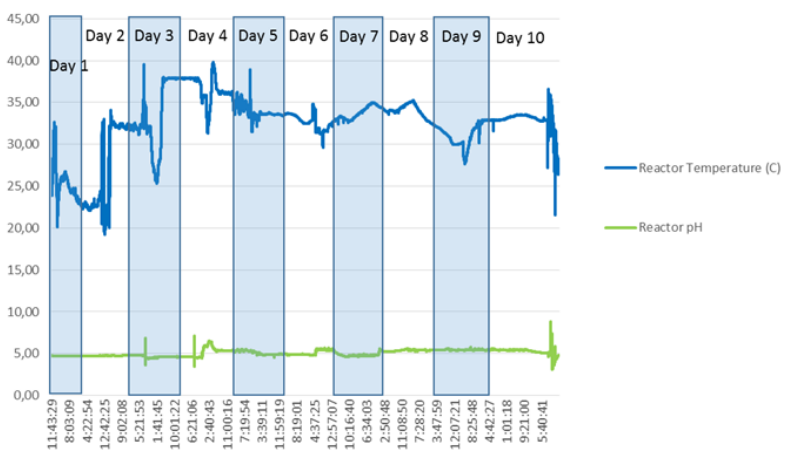

Figure 3. Bioreactor Temperature and $\mathrm{pH}$ during the Finnish Run 6 (24.3.2014 - 3.4.2014). 
In Figures 4 and 5 the temperature and $\mathrm{pH}$ measurement data from Hydrolyzer and Bioreactor during Run 7 in Poland are presented.

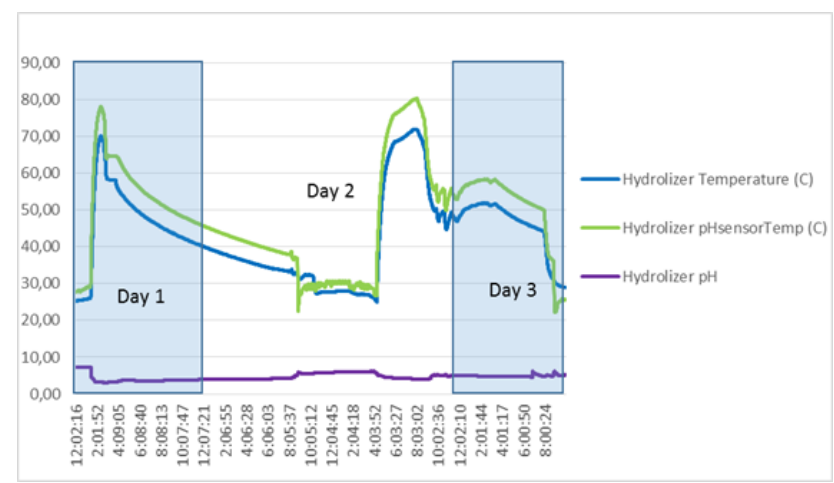

Figure 4. Hydrolyzer Temperature and $\mathrm{pH}$ during the Polish Run 7 (23.6.2014 - 25.6.2014).

In the Polish example, first the temperature of the Hydrolyzer had been risen up to $80^{\circ} \mathrm{C}$ for hygienization purposes and after that the substrate has been pumped to the Bioreactor in which the temperature had been kept as $35^{\circ} \mathrm{C}$. In addition, Hydrolyzer heating had been started again, simultaneously with a bioprocess run in the Bioreactor (Day 2).

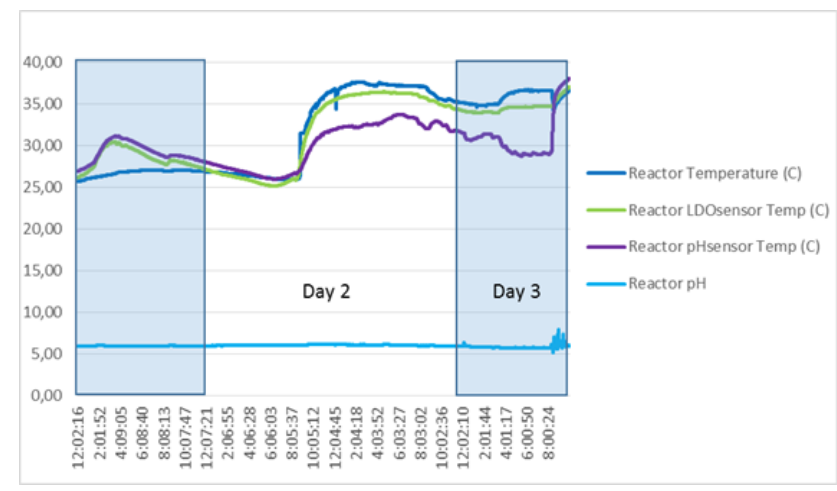

Figure 5. Bioreactor Temperature and $\mathrm{pH}$ during the Polish Run 7 (23.6.2014 - 25.6.2014).

In Figures 6 and 7 the temperature and $\mathrm{pH}$ measurement data from Hydrolyzer and Bioreactor during the final test run in Sweden are presented.

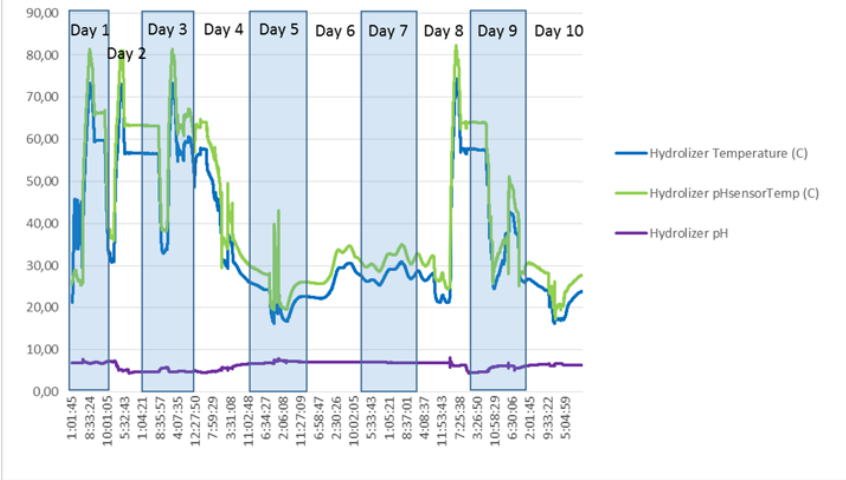

Figure 6. Hydrolyzer Temperature and $\mathrm{pH}$ during the Swedish Run 4 (22.9.2014 - 2.10.2014).

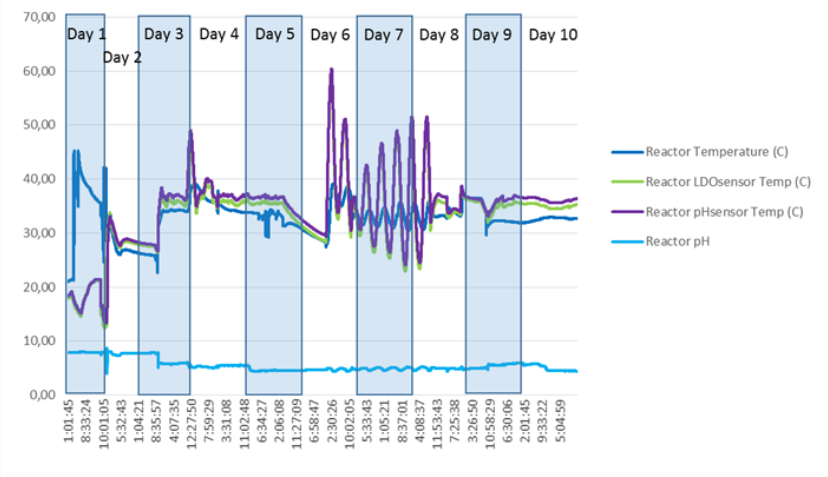

Figure 7. Bioreactor Temperature and $\mathrm{pH}$ during the Swedish Run 4 (22.9.2014 - 2.10.2014).

The Bioreactor was manufactured of stainless steel and for the temperature control it has a water jacket which reaches about half of the height of the Bioreactor. To the water jacket it is possible to introduce either hot water from the hot-water tank or cold water from the cooler. The objective was to gain a wide surface for the heating and cooling so that point-form high surface temperatures would not kill or hamper the bacterial strains. For the Bioreactor's temperature control these brought challenges as in principle a simple heating process changed into a process that includes two time constants. It can be concluded that the water jacket around the Bioreactor is unnecessary large, which caused too much delay for the temperature control. By speeding up the temperature measurement of exiting heating or cooling water it is possible to improve the cascading structure of the adjustment.

The Bioreactor's temperature sensor is located in the bottom where temperature cannot change very rapidly. Bioreactor mixing with airlift does not always reach the lower parts of the Bioreactor. Dissolved oxygen electrode and $\mathrm{pH}$-electrode locate in the middle part of the Bioreactor and they both contain a temperature sensor. The temperature sensor of $\mathrm{pH}$-electrode, however, is faster to react than the temperature sensor of 
the dissolved oxygen electrode. $\mathrm{pH}$-electrode has a considerably smaller mass and in addition, the tip of the electrode, in which the temperature sensor is locating, is narrow. Hence the values that these two temperature sensors are showing might differ from each other.

$\mathrm{PH}$ adjustment of the Bioreactor was known to be challenging and even more efforts should have been put to that control. However, $\mathrm{pH}$ has remained surprisingly stable. Temperature compensation of the $\mathrm{pH}$ electrode rectifies the change of the current from $\mathrm{pH}$ electrode that is due to temperature, but also the $\mathrm{pH}$ of a substance is changing as temperature changes and that change is not linear.

The emptying of the Bioreactor did not function well. Continuous recovery of products was not tried because the Stabilizer was not insulated and the risk of emitted $\mathrm{H}_{2} \mathrm{~S}$ from the process broth could not be handled.

\section{Conclusions}

A lot of challenges were faced in ABOWE because of the very tight time schedule for engineering and construction of the mobile biorefinery pilot plant. Besides, there were only two months available for test runs in each of the three countries. There came out some problems which probably were due to insufficient time to implement all planned settings before the test runs had to be started. Planned systems were not always put completely into operation because of their deficiencies or because there were not time for training. This led to situation where the major parts of the system were operated manually although automatic functions had been designed.

From the microbiology side, the combinations of the natural microbial flora with some added microbial strains should be further tested in future. It would be necessary to continue the experiments with the cellulosic waste in order to demonstrate the full potential of the biorefinery principle. It could then also be possible to combine the control with the activities of the natural flora into an overall bioprocess steering.

In ABOWE Polish tests pure cultures of microbes were used. However, volatile fatty acids (VFA) can be produced from various organic wastes also with mixed cultures under anaerobic conditions (Agler et al, 2011). According to Agler et al. (2011) and Spirito et al. (2014), undefined mixed cultures (or unrestricted microbiomes) offer a clear advantage over pure cultures because open microbiomes can, due to the metabolic flexibility, tolerate the complexity and variability of substrates. Moreover, sterilization and aeration can be eliminated in many cases since undefined mixed cultures can grow under non-aseptic conditions and often in anaerobiosis, too. (den Boer et al, 2016b)

More test runs would be needed for fully optimizing the effects of various parameters to further improve the yield of the biorefining. Gaining and maintaining the optimal conditions for bioprocesses is demanding as many raw materials and their concentrations or the products can affect even radically to the process and its velocity. From the adjustment technology point of view it is the question of a multi-parameter process and in addition the events are nonlinear.

It is possible to compile a mathematical model of the Bioreactor that can be simulated. The parameters have to be known as well as the interrelations between parameters. Based on measurement data, the Bioreactor operations could be modelled and transfer functions could be gained. Then various adjustment solutions should be simulated with a numerical computing program. For example, it would be possible, with logging data from automation system with regular intervals, to further model the temperature behavior of the Bioreactor such as temperature measurement and adjustment as well as to try cascade adjustment. To calculate heating and cooling power there should be, in addition to temperature measurement, also flow measurement in place. In measurements-based modelling, the adjustment should be done manually so that the effect of steering would be seen in the responses from the measurements reliably enough.

Implementation of degradative and recycling function of the Nature's microbiota into industrial applications is the leading principle in the Finnoflag Oy's biorefinery technology. This requires understanding of the interactions between the biomass (whose composition is subjected to variations), its natural flora, and the added strains and enzymes. The main purpose of the biorefinery pilot plant experiments was to give a reliable proof of concept on the industrially important substances producible in a sustainable way. This goal was achieved successfully, and several overall challenges were overcome during the testing in three countries. (Hakalehto et al, 2016b)

According to the analysis on the climatic impacts of the biotechnological processes, a combined production strategy including both 1 . biorefining of chemicals from biomasses and 2. biogas process based on its residues could add value, if technologies were applied together with a cascading principle. This approach could also bring along an effective solution for eliminating the waste problems. In this case the biorefining and the preliminary hydrolysis should take place preferably in a consolidated bioprocess (CBP) where the waste macromolecules would be hydrolyzed simultaneously with the actual upstream process (Hakalehto, 2015). In case of the pilot plant the hydrolysis was partially going on also after the transfer of the pretreated substrate from the Hydrolyzer into the Bioreactor. Fast moving of the broth, from where the biochemicals were collected using the CBP principle, with a subsequent transfer of the biomass from the biorefinery into a biogas production unit, could optimally contribute in the 
lowering of any climatic effect of the waste treatment. Then the biogas process could be boosted by the remaining organic acids in the solid fraction. Also the uplifted biochemical and gas production levels after optimization of the piloting and scale up trials would produce improvements in greenhouse gas reduction. (Hakalehto, 2015; Hakalehto et al, 2016b)

den Boer et al. (2016b) define some potential configurations of the biorefinery process in the waste management system and synergies of co-location with other waste handling plants. Scenario 1 is a biorefinery combined with a municipal incineration plant for residual waste. Separate collection and treatment of biowaste improves the calorific values of residual waste. Building biorefinery, as a central biowaste recycling plant next to an incineration plant would enable heat generated in the incineration to be utilized for heating up the biorefinery process. Scenario 2 co-locates a biorefinery with a biogas plant within one regional biowaste treatment plant. The biorefinery would add value in the pretreatment of separately collected biowaste by first processing high value commercial products from it. The residual biodegradable fraction of biorefinery process could be further fed to a biogas plant in order to produce energy. The benefit from combining the biorefinery and biogas plant is that the excess heat of the biogas plant could be used to heat up the biorefinery process. Scenario 3 considers locating biorefinery in combination with an industrial wastewater treatment plant. Biorefinery technology could be implemented at a range of food processing industries such as a potato chips and snacks factory. Nowadays, the large quantities of biowaste that the industry generates need to be transported to a remote biogas plant. The benefit would be to include the biorefinery process directly on-site, which saves in the transportation costs. The plant would also benefit from diversification of products they generate and options for new business. For the treatment of the residues of the biorefinery process, the optimal solution would be to utilize existing wastewater treatment plant. Food industry plants normally generate large amounts of wastewater which needs to be treated directly on-site. The most common method to treat wastewater sludges is wet digestion. Here, the co-digestion of wastewater sludges and residues from the biorefinery process would be the most beneficial solution. The heat generated in the digestion plant could be again utilized for the biorefinery process. Stabilized sludges from the wet digestion could be used as high quality fertilizer to close the natural cycle of nutrients. (den Boer et al, 2016b)

\section{Acknowledgements}

The ABOWE project was funded by the European Union (European Regional Development Fund). Construction of the mobile biorefinery pilot plant was co-funded by the Ministry of Employment and
Economy in Finland and the Regional Council of Pohjois-Savo, Finland.

\section{References}

M.T. Agler, B.A. Wrenn, S.H. Zinder, and L.T. Angenent. Waste to bioproduct conversion with undefined mixed cultures: the carboxylate platform. Special Issue - Applied Microbiology, Trends in Biotechnology, 29(2), 2011.

G. Bastin and D. Dochain, On-line estimation and adaptive control of bioreactors. Process Measurement and Control 1. Amsterdam: Elsevier Science Publishers B.V., 1990.

E. den Boer, A. Łukaszewska, W. Kluczkiewicz, D. Lewandowska, K. King, A. Jääskeläinen, A. Heitto, R. Laatikainen, and E. Hakalehto. Biowaste conversion into carboxylate platform chemicals. In: E. Hakalehto (ed.) Microbiological Industrial Hygiene. New York, USA: Nova Science Publishers, Inc., 2016a.

E. den Boer, A. Łukaszewska, W. Kluczkiewiczc, D. Lewandowska, K. King, T. Reijonen, T. Kuhmonen, A. Suhonen, A. Jääskeläinen, A. Heitto, R. Laatikainen, and E. Hakalehto. Volatile fatty acids as an added value from biowaste. Waste Manag., 58: 62-69, $2016 \mathrm{~b}$.

E. Hakalehto (ed.) Alimentary microbiome - a PMEU Approach. New York, USA: Nova Science Publishers, Inc., 2012.

E. Hakalehto. Interactions of Klebsiella sp. with other intestinal flora. In: L.A. Pereira and A. Santos (eds.) Klebsiella infections: Epidemiology, pathogenesis and clinical outcomes. New York, USA: Nova Science Publishers, Inc., 2013.

E. Hakalehto. Enhanced microbial process in the sustainable fuel production. In: J. Yan (ed.) Handbook of clean energy systems. Chichester, UK: Wiley JR \& Sons. Inc, 2015.

E. Hakalehto and O. Hänninen. Gaseous CO2 signal initiate growth of butyric acid producing Clostridium butyricum both in pure culture and in mixed cultures with Lactobacillus brevis. Can J Microbiol, 58(7): 928-931, 2012.

E. Hakalehto, T. Humppi, and H. Paakkanen. Dualistic acidic and neutral glucose fermentation balance in small intestine: Simulation in vitro. Pathophysiology, 15(4): 211-220, 2008.

E. Hakalehto and L. Heitto. Minute microbial levels detection in water samples by Portable Microbe Enrichment Unit technology. Environment and Natural Resources Research, 2(4): 80-88, 2012.

E. Hakalehto, A. Jääskeläinen, T. Humppi, and L. Heitto. Production of energy and chemicals from biomasses by micro-organisms. In: E. Dahlquist (ed.) Biomass as energy source: resources, systems and applications. London, UK: CRC Press, Taylor \& Francis Group, 2013.

E. Hakalehto, A. Heitto, H. Andersson, J. Lindmark, J. Jansson, T. Reijonen, A. Suhonen, A. Jääskeläinen, R. Laatikainen, S. Schwede, P. Klintenberg, and E. Thorin. Some remarks on processing of slaughterhouse wastes from ecological chicken abattoir and farm. In: E. Hakalehto (ed.) Microbiological Industrial Hygiene. New York, USA: Nova Science Publishers, Inc., 2016a.

E. Hakalehto, A. Heitto, A. Suhonen, and A. Jääskeläinen. ABOWE project concept and Proof of Technology. In: E. 
Hakalehto (ed.) Microbiological Industrial Hygiene. New York, USA: Nova Science Publishers, Inc., 2016b.

E. Hakalehto, A. Heitto, H. Niska, A. Suhonen, R. Laatikainen, L. Heitto, E. Antikainen, and A. Jääskeläinen. Forest industry hygiene control with reference to waste refinement. In: E. Hakalehto (ed.) Microbiological Industrial Hygiene. New York, USA: Nova Science Publishers, Inc., 2016c.

M. Hell, C. Bernhofer, S. Huhulescu, A. Indra, F. Allerberger, M. Maass, and E. Hakalehto. How safe is colonoscopereprocessing regarding Clostridium difficile spores? The Journal of Hospital Infection, Vol. 76, Supplement 1: Abstracts, 8th International Congress of the Hospital Infection Society, 10-13 October 2010, Liverpool, UK, S21-22

A. Jääskeläinen and E. Hakalehto, $A B O W E$ and Beyond Baltic Sea Biorefinery Piloting 2014. ABOWE Biorefinery Final Summary Report. Kuopio, Finland: Savonia University of Applied Sciences, 2015. Available at: http://portal.savonia.fi/amk/sites/default/files/pdf/eng/abo we/ABOWE_Biorefinery_Final_Summary_Report

A. Jääskeläinen and E. Hakalehto. Biorefinery education as a tool for teaching sustainable development. In: W. Leal Filho (ed.) Implementing Sustainability in the Curriculum of Universities. Approaches, Methods and Projects. Cham, Germany: Springer International Publishing, 2018.

R. Laatikainen, P. Laatikainen, and E. Hakalehto. Quantitative quantum mechanical nmr analysis: The superior tool for analysis of biofluids. In: Proceedings of the 1st Int. Electron. Conf. Metabolomics, 1-30 November 2016. Sciforum Electronic Conference Series, 1, C005. doi:10.3390/iecm-1-C005

C.M. Spirito, H. Richter, K. Rabaey, A.J.M. Stams, and L.T. Angenent. Chain elongation in anaerobic reactor microbiomes to recover resources from waste. Current Opinion in Biotechnology, 27: 115-122, 2014.

S. Schwede, E. Thorin, J. Lindmark, P. Klintenberg, A. Jääskeläinen, A. Suhonen, R. Laatikainen, and E. Hakalehto. Using slaughterhouse waste in a biochemical based biorefinery -results from pilot scale tests. Environmental Technology, 10: 1275-1284, 2017. 